Bond University

Research Repository

\title{
Mood and interpersonal functioning in heavy smokers
}

Lyvers, M.; Thorberg, F. A.; Dobie, A.; Huang, Ju; Reginald, P.

Published in:

Journal of Substance Use

DOI:

$10.1080 / 14659890802040807$

Licence:

Other

Link to output in Bond University research repository.

Recommended citation(APA):

Lyvers, M., Thorberg, F. A., Dobie, A., Huang, J., \& Reginald, P. (2008). Mood and interpersonal functioning in heavy smokers. Journal of Substance Use, 13(5), 308-318. https://doi.org/10.1080/14659890802040807

\footnotetext{
General rights

Copyright and moral rights for the publications made accessible in the public portal are retained by the authors and/or other copyright owners and it is a condition of accessing publications that users recognise and abide by the legal requirements associated with these rights.
}

For more information, or if you believe that this document breaches copyright, please contact the Bond University research repository coordinator. 


\section{Bond University}

\section{ePublications@bond}

$10-1-2008$

\section{Mood and interpersonal functioning in heavy smokers}

Michael Lyvers

Bond University, michael_lyvers@bond.edu.au

Fred Arne Thorberg

Bond University

Alana Dobie

Bond University

Joanna Huang

Bond University

Priya Reginald

Bond University

Follow this and additional works at: http://epublications.bond.edu.au/hss_pubs

\section{Recommended Citation}

Michael Lyvers, Fred Arne Thorberg, Alana Dobie, Joanna Huang, and Priya Reginald. (2008)

"Mood and interpersonal functioning in heavy smokers" ,, .

http://epublications.bond.edu.au/hss_pubs/256 
Mood and Interpersonal Functioning in Heavy Smokers

Michael Lyvers, Ph.D.

Fred Arne Thorberg, M.A.

Alana Dobie, PG Dip (psych)

Joanna Huang, PG Dip (psych)

Priya Reginald, PG Dip (psych)

Address correspondence to:

Associate Professor Michael Lyvers

Department of Psychology

Bond University

Gold Coast, Qld 4229 Australia

telephone: (61) (75) 5952565

facsimile: (61) (75) 5952672

e-mail: mlyvers@staff.bond.edu.au 


\begin{abstract}
Male and female adult heavy smokers $(n=96)$ and nonsmokers $(n=123)$ were compared on the Depression Anxiety Stress Scales (DASS), Adult Attachment Scale (AAS), Fear of Intimacy Scale (FIS), Negative Mood Regulation (NMR) Scale and Affect Intensity Measure (AIM). Compared to nonsmokers, smokers scored significantly higher on DASS-Stress, DASS-Anxiety, and DASSDepression, and significantly lower on NMR, AAS-Depend and AAS-Close. Smokers also scored marginally higher on FIS. Results suggest mood and relationship dysfunction in smokers, similar to the findings of a previous investigation of detoxified inpatients undergoing treatment for substance (alcohol, heroin, or methamphetamine) dependence.
\end{abstract}

KEYWORDS: smoking, nicotine, mood regulation, attachment 
Mood and Interpersonal Functioning in Heavy Smokers

Heavy smokers often report higher levels of negative affect than nonsmokers do (e.g., Brook, Cohen \& Brook, 1998; Ferdinand, Blum \& Verhulst, 2001; Thorberg \& Lyvers, 2005). Similarly, alcoholics and drug addicts report higher levels of negative affect in comparison to nonaddict control samples (Thorberg \& Lyvers, 2006a; Woody, Urschel \& Alterman, 1992). Thorberg and Lyvers (2006b) additionally found evidence of poorer interpersonal and relationship functioning in abstinent alcoholics and illicit drug (heroin, methamphetamine) addicts undergoing treatment for their substance disorder, in comparison to non-addict controls. Chronic heavy smoking is widely regarded as an addictive disorder and a variety of evidence suggests that many heavy smokers use tobacco as a means to regulate their moods and cope with stress (Ikard, Green, \& Horn, 1969; Thorberg \& Lyvers, 2005). For example, smokers often report that they smoke when feeling anxious, angry, stressed, sad or depressed (e.g., Russell, Peto, \& Patel, 1974) and say they expect smoking to help alleviate their negative moods (Brandon \& Baker, 1991; Copeland, Brandon \& Quinn, 1995). Furthermore, nicotine dependence is associated with elevated risk for major depression and anxiety disorders (Breslau, 1995) and with personality traits such as neuroticism and psychoticism (e.g., McCrae, Costa \& Bosse, 1978; Spielberger \& Jacobs, 1982).

Catanzaro and Mearns (1990) defined the concept of generalized expectancies for negative mood regulation (NMR) as beliefs concerning one's ability to terminate or alleviate negative mood states. Within the framework of Rotter’s $(1954,1982)$ social learning theory NMR expectancies are defined as cross-situational beliefs that some behavior or cognition will alleviate a negative mood (Catanzaro \& Greenwood, 1994). Given their relevance to self-regulatory processes, NMR expectancies should be crucial determinants of a number of aspects of coping with stress and negative affect.

NMR expectancies vary across individuals and are associated with different strategies to cope with or alleviate negative moods (Catanzaro \& Greenwood, 1994). Expectancies regarding 
emotional states appear to be relatively stable individual characteristics and are related to clinical and sub-clinical levels of distress. NMR expectancies are positively related to active coping and negatively related to dysphoric symptoms and depression (Brashares \& Catanzaro, 1994; Catanzaro, Horaney \& Creasey, 1995; Catanzaro \& Horlock, 1996; Kirsch, Mearns \& Catanzaro, 1990; Mearns, 1991; Mearns \& Mauch, 1998; Thorberg \& Lyvers, 2006a), and interacted with state anxiety to influence college students’ exam performance in a study by Catanzaro (1996). NMR expectancies thus appear to be negatively related to anxiety and depression and positively related to active coping strategies. Recently, several studies have reported relationships between low NMR expectancies and problem drinking (e.g., Catanzaro \& Laurent, 2004; Kassel, Jackson, Shannon \& Unrod, 2000) as well as addictive disorders (Thorberg \& Lyvers, 2006a).

NMR expectancies are also associated with the self-reported intensity of one's moods, or affect intensity. For example, Flett, Blankstein and Obertinsky (1996) found that NMR was negatively correlated with affect intensity and positively correlated with active coping. Affect intensity appears to be independent of the hedonic quality of mood states. Diener, Larsen, Levine and Emmons (1985) reported that the intensity of a person's positive emotions correlated about .70 with the intensity of their negative emotions. Thus some individuals report more intense emotions irrespective of whether the emotions are positive or negative. Larsen and Diener (1987) described affect intensity as “...stable individual differences in the strength with which individuals experience their emotions” (p. 2). Affect intensity can thus be distinguished from personality traits such as emotionality or neuroticism, which refer to the regular experience of negative emotion and the inclination to slip from a neutral or positive mental condition to a more negative state (Buss \& Plomin, 1975; Guilford \& Zimmerman, 1957). Thorberg and Lyvers (2006a) recently found low NMR and high affect intensity in individuals undergoing treatment for addictive disorders. Thus addicts appear to be characterized by mood regulation difficulties. The present study examined heavy smokers (defined here as those who smoke at least 15 cigarettes per day) to see whether they 
exhibit a similar pattern (low NMR and high affect intensity) to that observed in other types of addicts. This was anticipated as previous studies have reported higher levels of stress, anxiety, panic attacks and major depression among heavy smokers than among nonsmokers (e.g., Breslau, Kilbey, \& Andreski, 1994; Degenhardt \& Hall, 2001; Farrell et al., 1998; Patton et al., 1998). Other evidence suggests that individuals who experience frequent affective distress and negative life events are more likely to shift from experimental to regular smoking (Koval et al., 2000; Orlando, Ellicksen, \& Jinnett, 2001). Tobacco may be used by such individuals as a means of regulating mood and coping with stress. Research indicates that neurotic adolescents are at heightened risk to begin smoking (e.g., Cherry \& Kiernan, 1976; Sieber \& Angst, 1990). Both psychopathology and neuroticism appear to be associated with tobacco use onset and dependence (Breslau, 1995).

Bowlby’s (1982) theory of attachment proposed that humans and other primates are equipped by evolution with an attachment behavioral system that promotes infant bonding to an attachment figure. This behavioral system remains quiescent in the presence of the caregiver, but becomes activated when the attachment figure is not available, prompting the child to seek the caregiver for comfort, security and support (Ainsworth, Blehar, Waters \& Wall, 1978). Through the interaction with the caregiver the infant develops internal working models that contain information on how to communicate, express emotions, handle disappointment and emotional discomfort, and solve problems in relationships (Bowlby, 1973; Sroufe \& Fleeson, 1986). Consistent with this idea, links have been suggested between early attachment experiences and later adult attachment styles in romantic relationships (Hazan \& Shaver, 1987; Pistole, 1989). A variety of evidence indicates that adults who have a secure attachment style report more intimacy in their romantic relationships (Bartholomew \& Horowitz, 1991), higher relationship quality (Feeney, Noller \& Callan, 1994; Keelan, Dion \& Dion, 1998), fewer interpersonal problems (Pistole, 1989) and greater relationship length (Feeney, 1996; Feeney \& Noller, 1990) than individuals with insecure attachment styles. Furthermore, an insecure attachment style may increase the likelihood of developing harmful 
drinking or other drug usage patterns (Brennan \& Shaver, 1995; Burge et al., 1997; Cooper et al., 1998; Ognibene \& Collins, 1998).

A primary function of attachment is the interpersonal regulation of affective experiences (Sroufe \& Waters, 1977). Individuals with a secure style tend to seek social support to cope with emotional stress, whereas insecure individuals may seek other means of emotional regulation, such as use of alcohol or other mood-altering drugs (e.g., Brennan \& Shaver, 1995; Cooper, Shaver \& Collins, 1998; McNally et al., 2003). Dottan et al. (2003) found that detoxified outpatient heroin addicts and poly-drug abusers exhibited an insecure attachment style. A recent study by Thorberg and Lyvers (2006b) indicated that insecure attachment characterizes clients enrolled in addiction treatment programs compared to non-addict controls. Although some researchers have proposed a link between substance abuse/dependence and insecure attachment, no study to date has assessed the potential link between heavy smoking, arguably the most common form of drug dependence, and attachment.

Hazan and Shaver (1987) reported an association between insecure attachment and fear of intimacy. According to Descutner and Thelen (1991), intimacy is a human need that is crucial to mental health and psychosocial adjustment. They proposed that given the strong relationship between intimacy and various indices of adjustment (e.g., Horowitz, 1979), fear of intimacy may be a risk factor for emotional problems, including those associated with increased risk of substance abuse. Fear of intimacy was defined as “...the inhibited capacity of an individual, because of anxiety, to exchange thoughts and feelings of personal significance with another individual who is highly valued” (p.219). Consistent with Descutner and Thelen’s view, research by Thorberg and Lyvers (2006b) indicated that individuals with substance disorders reported higher levels of fear of intimacy than did non-addict controls. Descutner and Thelen found significant correlations between fear of intimacy, as assessed by their Fear of Intimacy Scale (FIS), and loneliness, lack of selfdisclosure and low social interaction. Doi and Thelen (1993) subsequently reported a significant 
positive correlation between the FIS and measures of loneliness, and significant negative correlations between the FIS, self-disclosure and relationship satisfaction. Based on these associations and work by Descutner and Thelen (1991), we anticipated higher levels of fear of intimacy among heavy smokers in the present study.

Although many researchers have proposed a link between heavy smoking and affective distress (e.g., Degenhardt \& Hall, 2001; Dugan, Lloyd, \& Lucas, 1999), no study to date has assessed potential relationships between smoking, NMR expectancies, affect intensity, attachment and fear of intimacy. In the present investigation, heavy smokers were examined on self-report indices of negative affect, mood regulation and interpersonal functioning in comparison to nonsmokers, using the same measures as in a previous study that compared detoxified inpatients undergoing treatment for substance (alcohol, heroin, or methamphetamine) dependence to nonaddict controls (Thorberg \& Lyvers, 2006ab). Based on the previous work cited above, smokers were expected to report lower levels of NMR expectancies and secure attachment, and higher levels of stress, anxiety, depression, affect intensity, and fear of intimacy, compared to nonsmokers.

\section{Method}

\section{Participants}

Participants were recruited from an Australian university campus (Bond University) as well as from three Australian cities (Gold Coast, Sydney, Melbourne), and consisted of 96 smokers (who smoked at least 15 cigarettes per day) and 123 nonsmokers (who had never smoked). The sample included 87 men and 132 women and had a mean age of 28.11 years $(S D=10.10)$. Participants were at least 18 years old. Most participants received a chocolate bar as an incentive, however to recruit more participants the last 59 of the 219 participants were paid $\$ 10$ for their time. The study’s protocol was approved by the Bond University Human Research Ethics Committee prior to commencement of data collection. 


\section{Materials}

Demographic/Smoking Status Questionnaire.This questionnaire was designed specifically for the present study to assess age, gender, education level, occupation, smoker status and various aspects of smoking.

Negative Mood Regulation (NMR) Scale. The NMR scale, a 30-item questionnaire developed by Catanzaro and Mearns (1990), assesses generalized expectancies to alleviate negative moods by one's own efforts (excluding the use of drugs). Participants are asked to indicate the degree to which they believe their use of various coping strategies can counteract a negative mood state. Each item is scored on a five point Likert scale ranging from “Strongly disagree” to “Strongly agree” in relation to a statement completing the stem, “ When I'm upset I believe that....”. Examples of items include "I’ll feel okay if I think about more pleasant things”, “I can forget about what’s upsetting me pretty easily,” and “I’ll end up feeling really depressed.” A high score indicates a strong belief that one can alleviate one’s own negative moods through nonpharmacological means. Factor analysis has shown that the NMR scale is unidimensional (Catanzaro \& Mearns, 1990). The scale has high internal consistency (Catanzaro \& Mearns, 1987) and test -retest reliability (Mearns, 1991). It correlates in theoretically predicted ways with instruments assessing anxiety, depression, emotional states and coping responses and has demonstrated discriminant validity from social desirability, depression and locus of control (Catanzaro, 1994; Catanzaro \& Mearns, 1990; Mearns, 1991).

Depression Anxiety Stress Scales (DASS). The DASS (Lovibond \& Lovibond, 2002) is a self-report questionnaire listing negative emotional symptoms and is divided into three subscales measuring depression, anxiety and stress. Participants rate the extent to which they have experienced each symptom over the past week on a four point Likert scale ranging from "Did not apply to me at all” to “Applied to me very much, or most of the time.” The DASS comes in a long form consisting of 42 items and a short form consisting of 21 items. The 21-item version was 
administered in the present study. Antony, Bieling, Cox, Enns and Swinson (1998) claimed that the 21-item version has several advantages over the longer version in terms of fewer items, a cleaner factor structure and smaller inter-factor correlations. Antony et al. also reported that the internal consistency and concurrent validity for the DASS-21 subscales ranged from acceptable to excellent.

The Affect Intensity Measure (AIM). The AIM is a 40-item scale designed to measure the intensity with which individuals typically experience both positive and negative emotions (Larsen, 1984). Participants respond on a six point Likert scale agreeing or disagreeing with statements such as "When I feel happy it is a strong sense of exuberance," "Calm and cool could easily describe me,” “When I’m nervous I feel shaky all over,” and “I can remain calm even on the most trying of days.” Evidence has attested to both the reliability and validity of the AIM (e.g., Flett, Blankstein, Bator \& Pliner, 1989; Goldsmith \& Walters, 1989; Larsen \& Diener, 1987).

Revised Adult Attachment Scale (AAS). The revised AAS (Collins, 1996) was designed to assess adult attachment style and relationship quality. This 18-item scale has three subscales, Close, Depend and Anxiety. The Close subscale assesses how comfortable the participant is with closeness and intimacy. The Depend subscale assesses the extent to which the participant feels they can depend on others to be available when needed. The Anxiety subscale assesses how anxious the individual feels about being abandoned or unloved. High scores on Close and Depend, and low scores on Anxiety, indicate a secure attachment style (Collins, 1996; Collins \& Read, 1990). Each item is scored on a five point Likert scale ranging from "Not at all characteristic of me" to "Very characteristic of me,” with some items reverse scored. There are six items for Close (e.g. "I find it relatively easy to get close to people”), six items for Depend (e.g. "I find it difficult to allow myself to depend on others“), and six items for Anxiety (e.g. “I often worry that romantic partners don’t really love me”). The AAS has demonstrated acceptable internal consistency and test-retest reliability (Collins \& Read, 1990). 
Fear of Intimacy Scale (FIS). Descutner and Thelen (1991) developed the 35-item FIS to assess the degree of inhibition of an individual's capacity to exchange thoughts and feelings of personal significance with another highly valued individual. Participants respond to item statements with regard to a current close relationship or an imagined one (e.g. "I would feel comfortable telling my partner about things in the past that I have felt ashamed of”). Each item is scored on a five point Likert scale ranging from "Not at all characteristic of me" to "Extremely characteristic of me". A high score on the FIS indicates a high fear of intimacy. Studies have indicated that the FIS has high reliability and internal consistency (Descutner \& Thelen, 1991; Terrell, Terrell \& Von Drashek, 2000), and highly significant correlations have been reported between the FIS and measures of loneliness and intimacy (Sherman \& Thelen, 1996).

\section{Procedure}

Participants were recruited via posted advertisements and by word of mouth in the general Australian urban community (Gold Coast, Sydney, Melbourne) and on the campus of Bond University. Participants completed the questionnaires at home and returned them in a provided selfaddressed return envelope. Instructions specified that no identifying information was to be written on any of the questionnaires, ensuring anonymity of all responses. Attached to the questionnaire was an explanatory statement identifying goals of the study and participation requirements. Of 250 questionnaire packets distributed, 219 (88\%) were returned with usable data. The response rate was high because no prospective participant was given the questionnaires unless they had agreed to participate and had taken the incentive offered (chocolate bar or \$10).

\section{Results}

\section{$\underline{\text { Correlational Analysis }}$}

Initially the relationships among all measures were examined by means of Pearson productmoment correlation coefficients across all participants. Preliminary analysis was conducted to 
ensure there was no serious violation of the assumptions of normality, linearity and homoscedasticity. Most of the expected relationships were obtained, as shown in Table 1.

Table 1. Intercorrelations between Negative Mood Regulation (NMR) scale, Affect Intensity

Measure (AIM), Depression, Anxiety and Stress Scales (DASS), Fear of Intimacy Scale (FIS), and Adult Attachment Scale (AAS) subscales Depend, Anxiety (Anxatt), and Close.

\begin{tabular}{|c|c|c|c|c|c|c|c|c|}
\hline & AIM & Stress & Anxiety & Depression & FIS & Depend & Anxatt & Close \\
\hline NMR & -.07 & $-.40 * *$ & $-.37 * *$ & $-.43 * *$ & $-.45^{* *}$ & $.40 * *$ & $-.40 * *$ & $.36^{* *}$ \\
\hline AIM & & $.27^{* *}$ & $.24^{* *}$ & .10 & $-.23 * *$ & .06 & .10 & $.26^{* *}$ \\
\hline Stress & & & $.69 * *$ & $.68 * *$ & $.30 * *$ & $-.30 * *$ & $.41^{* *}$ & $-.24 * *$ \\
\hline Anxiety & & & & $.68^{* *}$ & $.31^{* *}$ & $-.21^{* *}$ & $.34^{* *}$ & $-.23^{* *}$ \\
\hline Depression & & & & & $.31^{* *}$ & $-.25 * *$ & $.38 * *$ & $-.26^{* *}$ \\
\hline FIS & & & & & & $-.47 * *$ & $.50 * *$ & $-.61^{* *}$ \\
\hline Depend & & & & & & & $-.51^{* *}$ & $.53^{* *}$ \\
\hline Anxatt & & & & & & & & $-.38 * *$ \\
\hline
\end{tabular}

$* * p<.01$.

Group Comparisons

A two-way multivariate analysis of covariance (MANCOVA) was performed with the independent variables of smoker status (heavy smokers, nonsmokers) and gender, the covariate of age, and the dependent variables of NMR, AIM, FIS, DASS Anxiety, Depression and Stress, and AAS Depend, Anxiety (Anxatt), and Close scores. The multivariate effect of age was significant, $F(9,206)=2.72, p=.005$, justifying the inclusion of age as covariate. The multivariate effect of smoker status was significant, $F(9,206)=2.44, p=.012$. The multivariate effect of gender was also significant, $F(9,206)=5.08, p=.000$, but the smoking $X$ gender interaction was not.

Univariate effects of smoker status were significant for NMR, $F(1,214)=4.81, p=.029$; DASS Stress, $F(1,214)=9.29, p=.003$; DASS Anxiety, $F(1,214)=14.00, p=.000$; DASS 
Depression, $F(1,214)=6.70, p=.010$; AAS Depend, $F(1,214)=9.15, p=.003$; and AAS Close, $F(1,214)=6.99, p=.009$. For FIS the univariate effect approached significance, $F(1,214)=3.49$, $p=.063$. As shown in Table 2, compared to nonsmokers, smokers scored significantly higher on DASS-Stress, DASS-Anxiety, and DASS-Depression, and significantly lower on NMR, AASDepend and AAS-Close. Smokers also scored marginally higher on FIS than nonsmokers.

Table 2. Mean (SD) Negative Mood Regulation (NMR), Depression Anxiety Stress Scales (DASS), Affect Intensity Measure (AIM), Fear of Intimacy Scale (FIS), and Adult Attachment Scale (AAS) subscales Depend, Anxiety (Anxatt), and Close scores in smokers versus nonsmokers.

$$
\text { Smokers }(n=96) \quad \text { Nonsmokers }(n=123)
$$

$\begin{array}{lccr}\text { NMR } & 101.93(14.36) & * & 106.89(15.89) \\ \text { AIM } & 143.22(22.23) & & 141.84(20.03) \\ \text { Stress } & 15.25(9.56) & * * & 11.06(8.79) \\ \text { Anxiety } & 10.81(9.05) & * * & 5.93(7.27) \\ \text { Depression } & 10.03(9.03) & * * & 6.88(7.13) \\ \text { FIS } & 86.54(19.91) & & 80.16(18.86) \\ \text { Depend } & 2.98(0.71) & * * & 3.28(0.78) \\ \text { Anxatt } & 2.54(1.00) & & 2.37(0.92) \\ \text { Close } & 3.37(0.68) & * * & 3.65(0.79)\end{array}$

$* \mathrm{p}<.05, * * \mathrm{p}<.01$

The univariate effect of gender was significant for AIM, $F(1,214)=34.76, p=.000$, such that females $(M=148.47, S D=20.39)$ scored significantly higher than males $(M=133.30, S D=$ 18.52). The univariate effect of gender was also significant for DASS Stress, $F(1,214)=5.29, p=$ .023 , with females $(M=13.74, S D=9.87)$ again scoring higher than males $(M=11.61, S D=8.39)$. 
Females $(M=2.55, S D=1.03)$ also scored significantly higher than males $(M=2.29, S D=0.82)$ on AAS Anxiety (Anxious Attachment), $F(1,214)=4.79, p=.03$.

\section{Discussion}

As predicted, heavy smokers reported significantly higher levels of DASS stress, anxiety, and depression, and significantly lower levels of NMR, compared to nonsmokers. NMR was significantly negatively correlated with stress, anxiety, and depression, as found in previous research on detoxified inpatients undergoing addiction treatment (Thorberg \& Lyvers, 2006a) as well as in nonaddict samples (Brashares \& Catanzaro, 1994; Catanzaro, 1993; Catanzaro \& Greenwood, 1994; Catanzaro, Horaney \& Creasey, 1995; Kirsch, Mearns \& Catanzaro, 1990; Mearns, 1991; Mearns \& Mauch, 1998; Surman, 1999). Further, as predicted smokers scored significantly lower on the AAS attachment dimensions of Close and Depend than nonsmokers, indicating that smokers had less secure attachment styles on average than the nonsmokers in the present study. Smokers also scored higher on fear of intimacy than nonsmokers, but the difference fell just short of statistical significance. Unlike the Thorberg and Lyvers (2006a) study where inpatient addicts reported higher affect intensity than nonaddict controls, this variable as measured by AIM was not significantly higher in smokers than in nonsmokers in the present study.

The present findings are generally consistent with the notion that heavy smokers, like those dependent on drugs such as alcohol, heroin or methamphetamine, suffer from relatively impaired affect regulation and have lower confidence than nonsmokers do in their ability to self-regulate their negative moods. As discussed in Thorberg and Lyvers (2006a), the role (if any) of NMR in the development and maintenance of addictions, including smoking, is unclear. Perhaps the most plausible possibility is that low NMR may lead to regular substance use as a means of coping with affective distress (Catanzaro \& Laurent, 2004). Self-medication of negative affect is a commonly cited reason for using alcohol and other drugs (Johnston \& O’Malley, 1986; Newcomb et al., 1988) as well as for smoking (Brandon \& Baker, 1991; Copeland, Brandon \& Quinn, 1995; Russell, Peto, 
\& Patel, 1974; Shiffman, 1993). Another possibility is that the lower NMR and higher levels of stress, anxiety and depression reported by heavy smokers are consequences of nicotine withdrawal or dependence (Parrott \& Kaye, 1999). The present correlational findings cannot distinguish between these possibilities.

As predicted, smokers scored lower than nonsmokers on the AAS attachment dimensions of Close (how comfortable the participant is with closeness and intimacy) and Depend (how much the participant feels they are able to rely on others when needed), indicating relatively insecure attachment styles (Collins, 1996) in smokers. Similarly, Thorberg and Lyvers (2006b) found that detoxified inpatients undergoing addiction treatment scored significantly lower on Close and Depend than did nonaddict controls. As with the NMR and DASS variables, heavy smokers were clearly differentiated from nonsmokers on these measures. This fits with previous reports of positive associations between insecure attachment and substance use (Brennan \& Shaver, 1995; Burge et al., 1997; Cooper et al., 1998; Dottan et al., 2003; Ognibene \& Collins, 1998). Present results are also consistent with the notion that insecure attachment and fear of intimacy may be potential risk factors for heavy substance use (Thorberg \& Lyvers, 2006b), in this case smoking.

The direction of causation cannot be ascertained from the correlational findings of the present study. However, unlike the findings of Thorberg and Lyvers, where chronic alcohol or drug problems could have plausibly led to ongoing relationship difficulties in the addict sample which in turn might explain their AAS and FIS scores, smoking would seem unlikely to have caused the interpersonal difficulties suggested by smokers' scores on AAS and FIS in the present study. Thus among those who smoke heavily, many may do so for reasons of affective regulation in the absence of secure attachment.

The previous findings of Thorberg and Lyvers (2006a,b) indicated that detoxified inpatients undergoing addiction treatment reported comparatively lower levels of NMR and higher levels of negative moods, fear of intimacy and insecure attachment than nonaddicts did. The present findings 
indicate that a similar pattern characterizes heavy smokers, suggesting that generalized difficulty with affective regulation may be a common feature of diverse types of addictions. 


\section{References}

Ainsworth, M. D., Blehar, M. C., Waters, E., \& Wall, S. (1978). Patterns of attachment-A psychological study of the strange situation. New Jersey: Lawrence Erlbaum Associates Publishers.

Ajzen, I., \& Fishbein, M. (1980). Understanding attitudes and predicting social behavior. Englewood Cliffs, NJ: Prentice Hall.

Antony, M. M., Bieling, P. T., Cox, B. J., Enns, M. W., \& Swinson, R. P. (1998). Psychometric properties of the 42-item and 21-item versions of the depression anxiety stress scales in clinical groups and a community sample. Psychological Assessment, 10 (2), 176-181.

Bartholomew, K., \& Horowitz, L. M. (1991). Attachment styles among young adults: A test of a four-category model. Journal of Personality and Social Psychology, 61, 226-244.

Bowlby, J. (1973). Attachment and loss: Vol. 2. Separation: Anxiety and anger. London: Hogarth Press.

Bowlby, J. (1982). Attachment. New York: Basic Books.

Brandon, T. H., \& Baker, T. B. (1991). The Smoking Consequences Questionnaire: The subjective expected utility of smoking in college students. Psychological Assessment, 3, 484-491.

Brashares, H. J., \& Catanzaro, S. J. (1994). Mood regulation expectancies, coping responses, depression, and sense of burden in female caregivers of Alzheimer's patients. Journal of Nervous and Mental Disease, 182, 437-442.

Brennan, K. A., \& Shaver, P. R. (1995). Dimensions of adult attachment, affect regulation, and romantic relationship functioning. Personality and Social Psychology Bulletin, 21, 267-283. 
Breslau, N. (1995). Psychiatric comorbidity of smoking and nicotine dependence. Behavior Genetics, 25, 95-101.

Breslau, N., Kilbey, M. M., \& Andreski, P. (1994). DSM-III-R nicotine dependence in young adults: Prevalence correlates and associated psychiatric disorders. Addiction, 89, 743-753.

Brook, J. S., Cohen, P., \& Brook, D. W. (1998). Longitudinal study of co-occurring psychiatric disorders and substance use. Journal of the American Academy of Child and Adolescent Psychiatry, 37, 322-330.

Burge, D., Hammen, C., Davila, J., Daley, S. E., Paley, B., Lindberg, N., Herzberg, D., \& Rudolph, K. D. (1997). The relationship between attachment cognitions and psychological adjustment in late adolescent women. Development and Psychopathology, 9, 51-167.

Buss, A. H., \& Plomin, R. (1975). A temperament theory of personality. New York: Wiley.

Catanzaro, S. J. (1996). Negative mood regulation expectancies, emotional distress, and examination performance. Personality and Social Psychology Bulletin, 22 (10), 1023-1029.

Catanzaro, S. J. (1993). Mood regulation expectancies, anxiety sensitivity and emotional distress. Journal of Abnormal Psychology, 102 (2), 327-330.

Catanzaro, S. J. (1994). Discrimination of mood regulation expectancies from dysphoria: Confirmatory factor analytic findings. Assessment, 1, 53-58.

Catanzaro, S. J. (1996). Negative mood regulation expectancies, emotional distress, and examination performance. Personality and Social Psychology Bulletin, 22 (10), 10231029.

Catanzaro, S. J., \& Greenwood, G. (1994). Expectancies for negative mood regulation, coping and dysphoria among college students. Journal of Counselling Psychology, 41, 34-44.

Catanzaro, S. J., Horaney, F., \& Creasey, G. (1995). Hassles, coping, and depressive symptoms in an elderly community sample: The role of mood regulation expectancies. Journal of Counseling Psychology, 42 (3), 259-265. 
Catanzaro, S. J., \& Horlock, B.A. (1996, July). Mood regulation expectancies predict situational coping responses, but not changes in depression (summary). Proceedings and Abstracts of the Annual Meeting of the American Psychological Association, 8, 111.

Catanzaro, S. J., \& Laurent, J. (2004). Perceived family support, negative mood regulation expectancies, coping, and adolescent alcohol use: Evidence of mediation and moderation effects. Addictive Behaviors, 29, 1779-1797.

Catanzaro, S. J., \& Mearns, J. (1987, August). Measuring generalized expectancies for negative mood regulation. Paper presented at the annual meeting of the American Psychological Association, New York.

Catanzaro, S. J., \& Mearns, J. (1990). Measuring generalized expectancies for negative mood regulation: Initial scale development and implications. Journal of Personality Assessment, 54, 546-563.

Cherry, N., \& Kierman, K. (1976). Personality scores and smoking behaviour. British Journal of Preventive and Social Medicine, 30, 123.131.

Collins, N. L. (1996). Working models of attachment: Implications for explanation, emotion, and behavior. Journal of Personality and Social Psychology, 71, 810-832.

Collins, N. L., \& Read, S. J. (1990). Adult attachment, working models and relationship quality in dating couples. Journal of Personality and Social Psychology, 58, 644-663.

Cooper, M. L., Shaver, P. R., \& Collins, N. L. (1998). Attachment styles, emotion regulation, and adjustment in adolescence. Journal of Personality and Social Psychology, 74, 1380-1397.

Copeland, A. L., Brandon, T. H., \& Quinn, E. P. (1995). The Smoking Consequences Questionnaire-Adult: Measurement of smoking outcome expectancies of experienced smokers. Psychological Assessment, 7, 484-494. 
Degenhardt, L., \& Hall, W. (2001). The relationship between tobacco use, substance-use disorders and mental health: Results from the National Survey of Mental Health and Well-Being. Nicotine and Tobacco Research, 3, 225-234.

Descutner, C. J., \& Thelen, M. H. (1991). Development and validation of a fear-of-intimacy scale. Journal of Consulting and Clinical Psychology, 3 (2), 218-225.

Diener, E., Larsen, R. J., Levine, S., \& Emmons, R. A. (1985). Frequency and intensity: The underlying dimensions of affect. Journal of Personality and Social Psychology, 48, 1253-1265.

Doi, S. C., \& Thelen, M. H. (1993). The fear of intimacy scale: Replication and extension. Psychological Assessment, 5 (3), 377-383.

Dottan, R. F., Cohen, O., Iwaniec, D., Sapir, Y., \& Weizman, A. (2003). The drug-user husband and his wife: Attachment styles, family cohesion and adaptability. Journal of Substance Use and Misuse, 38 (2), 271-292.

Dugan, S., Lloyd, B., \& Lucas, K. (1999). Stress and coping as determinants of adolescent smoking behaviour. Journal of Applied Social Psychology, 29, 870-888.

Farrell, M., Howes, S., Taylor, C., Lewis, G., Jenkins, R., Bebbington, P., Jarvis, M., Brugha, T., Gill, B., \& Meltzer, H. (1998). Substance misuse and psychiatric comorbidity: An overview of the OPCS National Psychiatric Morbidity Survey. Addictive Behaviors, 32(6), 909-918.

Feeney, J. A. (1996). Attachment, caregiving, and marital satisfaction. Personal Relationships, 3, 401-416.

Feeney, J. A., \& Noller, P. (1990). Attachment style as a predictor of adult romantic relationships. Journal of Personality and Social Psychology, 58, 281-291. 
Feeney, J. A., Noller, P., \& Callan, V. J. (1994). Attachment style, communication and satisfaction in the early years of marriage. In K. Bartholomew \& D. L. Perlman (Eds.), Advances in personal relationships: Vol. 5, Adult attachment relationships (pp. 269-308). London: Kingsley.

Ferdinand, R. F., Blum, M., \& Verhulst, F. C. (2001). Psychopathology in adolescence predicts substance use in young adulthood. Addiction, 96, 861-870.

Flett, G. L., Blankstein, K. R., \& Obertinsky, M. (1996). Affect intensity, coping style, mood regulation expectancies, and depressive symptoms. Personality and Individual Differences, 20, 221-228.

Flett, G. L., Blankstein, K. R., Bator, C., \& Pliner, P. (1989). Affect intensity and self-control of emotional behaviour. Personality and Individual Differences, 10, 1-5.

Goldsmith, R. E., \& Walters, H. (1989). A validity study of the affect intensity measure. Journal of Social Behavior and Personality, 4, 133-140.

Guilford, J. P., \& Zimmerman, S. (1957). Fourteen dimensions of temperament. Psychological Monographs, 70 (Whole No. 417).

Hazan, C., \& Shaver, P. (1987). Romantic love conceptualised as an attachment process. Journal of Personality and Social Psychology, 52, 511-524.

Horowitz, L. M. (1979). On the cognitive structure of interpersonal problems treated in psychotherapy. Journal of Consulting and Clinical Psychology, 47, 5-15.

Ikard, F. F., Green, P. E., \& Horn, D. (1969). A scale to differentiate between types of smoking as related to the management of affect. International Journals of the Addictions, 4, 649-659.

Johnston, L. D., \& O’Malley, P. M. (1986). Why do the nation's students use drugs and alcohol? Self-reported reasons from nine national surveys. Journal of Drug Issues, 16, 29-66. 
Kassel, J. D., Jackson, S. I., Shannon, I., \& Unrod, M. (2000). Generalized expectancies for negative mood regulation and problem drinking among college students. Journal of Studies on Alcohol, 61 (2), 332-357.

Keelan, J. P. R., Dion, K. K., \& Dion, K. L. (1998). Attachment style and relationship satisfaction: test of a self-disclosure explanation. Canadian Journal of Behavioral Science, 30 (1), 24-35.

Kirsch, I., Mearns, J., \& Catanzaro, S. J. (1990). Mood-regulation expectancies as determinants of dysphoria in college students. Journal of Counseling Psychology, 37 (3), 306-312.

Koval, J. J., Pederson, L. L., Mills, C. A., McGrady, G.A., \& Carvajal, S.C. (2000). Models of the relationship of stress, depression, and other psychosocial factors to smoking behaviour: A comparison of a cohort of students in grades 6 and 8. Preventive Medicine, 30, 462-477.

Larsen, R. J. (1984). Theory and measurement of affect intensity as an individual difference characteristic. Dissertation Abstracts International, 85, 2297B (University Microfilms No. 84-22112).

Larsen, R. J., \& Diener, E. (1987). Affect intensity as an individual difference characteristic: A review. Journal of Research in Personality, 21, 1-39.

Lovibond, S. H., \& Lovibond, P. F. (2002). Manual for the Depression Anxiety Stress Scales 2nd edition. Sydney: Psychology Foundation.

McCrae, R. R., Costa, P. T., \& Bosse, R. (1978). Anxiety, extraversion, and smoking. British Journal of Social and Clinical Psychology, 17, 269-273.

McNally, A. M., Palfai, T. P., Levine, R. V., \& Moore, B. M. (2003). Attachment dimensions and drinking-related problems among young adults. The mediational role of coping motives. Addictive Behaviors, 28, 1115-1127. 
Mearns, J. (1991). Coping with a break-up: Negative mood regulation expectancies and depression following the end of a romantic relationship. Journal of Personality and Social Psychology, $60,327-334$.

Mearns, J., \& Mauch, T. (1998). Negative mood regulation expectancies predict anger among police officers and buffer the effects of job stress. Journal of Nervous and Mental Disease, 186, 120-125.

Newcomb, M. D., Chou, C. P., Bentler, P. M. \& Huba, G. J. (1988). Cognitive motivations for drug use among adolescents: Longitudinal tests of gender differences and predictors of change in drug use. Journal of Counseling Psychology, 35, 426-438.

Ognibene, T. C., \& Collins, N. L. (1998). Adult attachment styles, perceived social support and coping strategies. Journal of Social and Personal Relationships, 15, 323-345.

Orlando, M., Ellickson, P. L., \& Jinnett, K. (2001). The temporal relationship between emotional distress and cigarette smoking during adolescences and young adulthood. Journal of Consulting and Clinical Psychology, 69, 959-970.

Parrott, A. C., \& Kaye, F. J. (1999). Daily uplifts, hassles, stresses and cognitive failures: In cigarette smokers, abstaining smokers, and non-smokers. Behavioural Pharmacology, 10, 639-646.

Patton, G. C., Carlin, J. B., Coffey, C., Wolfe, R., Hibert, M., \& Bowes, G. (1998). Depression, anxiety and smoking initiation: A prospective study over three years. American Journal of Public Health, 88(10), 1518-1522.

Pistole, M. C. (1989). Attachment in adult romantic relationships: Style of conflict resolution and relationship satisfaction. Journal of Social and Personal Relationships, 6, 505-510.

Rotter, J. B. (1954). Social learning and clinical psychology. New York: Prentice Hall.

Rotter, J. B. (1982). The development and application of social learning theory. New York: Praeger. 
Russell, M.A. H., Peto, J., \& Patel, U.A. (1974). The classification of smoking by facial structure of motives. Journal of Royal Statistical Society Series A, 137, 313-333.

Sherman, M. D. \& Thelen, M. H. (1996). Fear of intimacy scale: Validation and extension with adolescents. Journal of Social and Personal Relationships, 13 (4), 507-521.

Shiffman, S. (1993). Assessing smoking patterns and motives. Journal of Consulting and Clinical Psychology, 61, 732-742.

Sieber, M. F., \& Angst, J. (1990). Alcohol, tobacco and cannabis: 12-year longitudinal associations with antecedent social context and personality. Drug and Alcohol Dependence, 25 (3), 281292.

Spielberger, C. D., \& Jacobs, G. A. (1982). Personality and smoking behaviour. Journal of Personality Assessment, 46, 396-403.

Sroufe, L. A. \& Fleeson, J. (1986). Attachment and the construction of relationships. In W. Hartup \& Z. Rubin (Eds.), Relationships and development (pp. 51-71). Hillsdale, NJ: Erlbaum.

Sroufe, L. A. \& Waters, E. (1977). Attachment as an organizational construct. Child Development, 48, 1184-1199.

Surman, A. T. (1999). Negative mood regulation expectancies, coping, and depressive symptoms among American nurses. The Journal of Social Psychology, 139 (4), 540-543.

Terrell, F., Terrell, I. S., \& Von Drashek, S. R. (2000). Loneliness and fear of intimacy among adolescents who were taught not to trust strangers during childhood. Adolescence, 35(140), 611-616.

Thorberg, F. A., \& Lyvers, M. (2005). Mood and interpersonal functioning in female university student smokers. Presented at the 17th Annual Convention of the American Psychological Society, Los Angeles, CA May 26-29.

Thorberg, F. A., \& Lyvers, M. (2006a). Negative Mood Regulation (NMR) expectancies, mood, and affect intensity among clients in substance disorder treatment facilities. Addictive Behaviors, 31 (5), 811-820. 
Thorberg, F. A., \& Lyvers, M. (2006b). Attachment, fear of intimacy and differentiation of self among clients in substance disorder treatment facilities. Addictive Behaviors, 31 (4), $732-$ 737.

Woody, G. E., Urschel, H. C., \& Alterman, A. (1992). The many paths to drug dependence. In M. Glantz \& R. Pickens (Eds.), Vulnerability to drug abuse (pp. 491- 507). Washington, DC: American Psychological Association. 